\title{
O POEMA COMO UM DIAGRAMA ABERTO: A POESIA GRÁFICO-DIGITAL DE ANDRÉ VALLIAS ${ }^{1}$
}

\author{
Maíra Borges Wiese*
}

RESUMO: O poeta André Vallias configura-se como um dos nomes pioneiros da poesia digital. Em 1991, foi curador, juntamente com Friedrich Block, da "Primeira Mostra Internacional de Poesia Digital", a P0es1s, e publicou poemas multimídias e hipermídias em sites e antologias nacionais e internacionais. Em um artigo intitulado "Nous n'avons pas compris Descartes", Vallias define uma concepção de poema que guiará a sua primeira série de poemas digitais poemas gráficos, poemas-diagramas -, e retomada nas suas produções multimídia e hipermídia subsequentes. Trata-se da visão do poema como um "diagrama aberto", um poema que se constrói a partir de uma interrelação de códigos, liberto da predominância do signo verbal, dotados de intermidialidade. Este artigo propõe uma interpretação de três poemas desta primeira série, desenvolvidos através do software de desenho AutoCAD e posteriormente remediados para a interface da Web. As interpretações visam, em primeiro lugar, iluminar alguns dos possíveis sentidos desenvolvidos pelos poemas; e, em segundo, apontar a relação que os poemas estabelecem, por suas características, com aspectos da poética digital como um todo.

PALAVRAS-CHAVE: André Vallias. Poema-diagrama. Poesia digital. Intermidialidade.

\section{Introdução}

A noção de poema como diagrama aberto, expressão contida no título deste artigo, foi discutida por Vallias num texto de 1992 (republicado em 1997 na antologia Media Poetry), cujo título fazia referência a um poema homônimo (a seu poema inicial, um poema-manifesto): "We have not understood Descartes". Aqui, Vallias define a expressão acima referida:

\begin{abstract}
Diagrams, in accordance with the growing complexity and volume of information in our times, find in the computer an ideal stage for development and dissemination. Digital technology provides a basis for increasingly rapid and wideranging inter-relationships of codes, since the computer itself transforms text, sound, form, colour, and movement into digits. Starting with "Nous n'avons pas compris Descartes", I have come to see the poem as an "Open Diagram",
\end{abstract}

\footnotetext{
* Faculdade de Letras da Universidade de Coimbra. Imeio: mairawiese@hotmail.com.

${ }^{1}$ Este artigo é um recorte adaptado do terceiro capítulo da dissertação de mestrado intitulada $A$ poesia digital de André Vallias, escrita sob a orientação dos professores Doutor Manuel José Freitas Portela e Doutora Maria Marta Dias Teixeira Costa Anacleto, e defendida em novembro de 2012 na Universidade de Coimbra.
} 
operating under the sign of diversity. Poetry is set free from the domain of the text - logocentrism - and recovers its primordial meaning of "creation", from the Greek poiésis, 'making' (1997, p. 87).

A perspectiva do diagrama aberto relaciona-se com a poesia de Vallias de dois modos: a alguns dos seus primeiros poemas gráficos criados com o auxílio do software de desenho tridimensional, o AutoCAD, por configurarem-se semelhante à estrutura de um típico diagrama (estrutura gráfica representacional, caracterizada pelo estabelecimento de relações entre seus elementos); já o segundo modo, mais abrangente, por retirar da formação etimológica da palavra diagrama (dia + gramma) ${ }^{2}$ o sentido de "escrita", unindoa a concepção de abertura acima citada (numa provável referência à formulação de Umberto Eco em A obra aberta). Sobre o primeiro sentido, farei uma breve discussão quando da análise dos poemas. O sentido posterior é que neste momento nos interessa: o que Vallias quer dizer por "escrita aberta", ou seja, por uma escrita composta de uma inter-relação de códigos?

É preciso antes destacar que o sentido que aqui subjaz do termo "escrita" diz tanto respeito ao meio dominante de representação do pensamento ocidental (e aqui podemos mencionar tanto um sentido mais largo do termo, o de "linguagem verbal", quanto um estrito, o de grafia), como à escrita enquanto sinônimo de composição poética - já que Vallias relaciona "diagrama aberto" essencialmente a "poema". É justamente contra esta "predominância" da linguagem verbal e da escrita sobre as formas de realização do pensamento e da composição poética que Vallias se dirige.

Por que deveria a criação poética efetivar-se unicamente ou essencialmente através do signo verbal? Essa questão não é de modo alguma nova. O questionamento das formas do signo linguístico em sua relação com as mídias de produção e recepção ocuparam amplamente as preocupações poéticas do século $\mathrm{XX}$, resultando em várias composições voltadas a uma inter-relação entre aquele e outros códigos - os visuais, sonoros, matemáticos, etc. Assim

\footnotetext{
${ }^{2}$ Em grego, gramma deriva de graphein (escrever), ou graphé (letra do alfabeto). Vallias, desse modo, une o sentido etimológico da palavra "diagrama" com o seu sentido hoje usual, o de figura representativa feita de sinais gráficos (linhas).
} 
como os movimentos poéticos experimentais deste século, Vallias buscou encontrar formas de expressão da linguagem (e da poesia) não somente atrelada aos seus códigos tradicionais, mas refletida em outros códigos (característica das obras intermidiais), ou inserida, como um dos componentes, num processo dialógico de uma obra multimídia.

$\mathrm{Na}$ década de 90, é nas ferramentas automáticas de composição do computador que Vallias vê um meio novo e rico de exploração dessa interrelação de códigos (influenciado pelas ideias de Vilém Flusser acerca das novas tecnologias, essencialmente as computacionais). Aqui surge a sua reconhecida poesia digital, sendo sua percepção do poema como um "diagrama aberto" bastante pertinente dentro da poética digital como um todo. Observemos, por exemplo, esta definição pontual do livro p0es1s: The Aesthetics of Digital Poetry:

[...] digital poetry "applies to artistic projects that deal with the medial changes in language and language-based communication in computers and digital networks. Digital poetry thus refers to creative, experimental, playful and also critical language art involving programming, multimedia, animation, interactivity, and net communication" (Cit. por. Funkhouser, 2007, p. 22).

Além do diálogo com os códigos visuais e sonoros, já presentes na poética vanguardista e experimental, os softwares de animação, as interfaces e conteúdos materialmente manipulados do computador, a internet, a programação, etc., são outros possíveis meios a serem experimentados pelos poetas digitais. A eles Vallias começou a se dedicar a partir da década de 90, quando substitui a aparelhagem da serigrafia pelo software de desenho gráfico tridimensional AutoCAD. Além deste, vieram outros: o Director, o Illustrator, o Flash... Outras formas começaram a ser desenvolvidas, como o poema cinético, multimídia, hipermídia e interativo.

A obra poética digital de André Vallias abrange todos esses tipos mencionados. Mas antes de sua investida nas formas multimídias e hipermídias, o poeta dedicou-se à relação entre a palavra e as formas gráficas, entre a criação poética e as estruturas sintéticas de representação (como o diagrama), entre o 
espaço virtual por trás da tela do computador e as formas de organização do objeto poético. Talvez influenciado, ou limitado, pelo ainda deficiente espaço (e os poucos recursos) que tinha o computador na esfera dos instrumentos tecnológicos no começo da década 90 (período de suas primeiras composições digitais), Vallias experimentou, inicialmente, os recursos de um software destinado especialmente ao desenho gráfico, o AutoCAD, e com ele criou as primeiras versões dos poemas que a seguir analisamos.

O avanço dos recursos computacionais nos anos seguintes (e da facilitação do acesso aos PCs) de igual modo influenciou as estruturas posteriores de seus poemas. Esses seus primeiros poemas gráficos, que surgiram como formas estáticas, destinados a uma visualização e leitura por meio de uma folha impressa (ou painel fotográfico), hoje, disponibilizados na interface da Web, incorporam outros códigos e modos de realização e recepção. É a esta "forma adaptada a Web" dos poemas gráficos digitais de Vallias que me dedico nos próximos tópicos.

\section{Poemas gráfico-digitais}

Esta série de poemas gráficos que se segue, elaborados, a maioria, nos primeiros anos da década de 90, representam os primeiros trabalhos poéticos digitais de Vallias. Desenvolvidos incialmente apenas em AutoCAD (o primeiro software significativo ao qual Vallias teve contato), possuem características significativas em comum. Uma delas deriva da própria mídia de elaboração (o software): as linhas brancas das coordenadas $x, y, z$ formam uma estrutura tridimensional sobre o fundo negro, um objeto que dialoga semântica $e$ formalmente com os signos verbais. Enquanto figuras tridimensionais, esses poemas assemelham-se a objetos físicos, dotados de corpo - mas objetos que, tais como as esculturas artísticas, são potencialmente comunicativos.

Uma segunda característica importante surge da relação entre a estrutura gráfica e os elementos verbais em poemas tais como Nous n'avons pas compris Descartes e Prthvī, configurando-os como poemas-diagramas. O 
diagrama tradicional possui a função de representar, através do estabelecimento de relações entre seus elementos gráficos e verbais, uma ideia, um conceito, um esquema, etc. Através do uso dessas relações, Vallias desenvolve diferentes formas visuais para expressar conceitos ou esquemas que, nestes poemas-diagramas, dizem respeito a aspectos da própria criação e formas poéticas, o que os confere um caráter autorreflexivo, metapoético.

Enquanto figuras gráficas, digramas-teóricos, objetos, esses poemas expressam uma intermidialidade que se tornou comum na poesia e que é uma das responsáveis pela sua complexidade, tanto de definição como de leitura. Kiene Brillenburg Wurth, no artigo "Multimediality, Intermediality, and Medially Complex Digital Poetry", explica-o3: "[intermediate artwotk] blends and rearranges familiar art forms in such a way as to make them indistinguishable and indivisible [...]. [the] words become like colors, colors like words, texts like buildings and spaces, sounds are spatially heard" (p. 12-15). Os poemasintermídia de Vallias, elaborados a partir de diferentes técnicas, num híbrido de gêneros artísticos, refletem justamente aquele seu questionamento inicial acerca das formas de expressão do signo verbal e do poema.

Por fim, uma terceira característica em comum entre os poemas seguintes é crucial: essa série gráfica, que surge como poemas estáticos, foi posteriormente remediada para a interface da web (a versão a qual hoje temos acesso em seu site). Essa remediação transformou os poemas em objetos animados - refletindo assim a tendência nas novas mídias a representarem objetos de forma animada e/ou multimídia ${ }^{4}$; mas apesar de animados, possuem um caráter intransigente, ou seja, precisam de uma ação do leitor para que a

\footnotetext{
${ }^{3}$ Este termo foi criado por Dick Higgins, em 1965, para designar as obras que, ao invés de combinarem formas e média distintos, os "fundem" conceitualmente, questionando-os (Uma versão do artigo foi publicada no livro Multimedia: from Wagner to virtual reality, Packer e Jordan, 2001, p. 27-32). Utilizarei a interpretação de Kiene Wurth (2006), mais clara e direcionada para a poesia digital, e que está disponível em: http://www.rilune.org/mono5/3 brillenburg.pdf

${ }^{4}$ Manovich (2001) propõe: "[there is] a general trend in modern society toward presenting more and more information in the form of time-based audiovisual moving image sequences, rather than as texts" (p. 87).
} 
obra se desenvolva ${ }^{5}$. Originariamente projetados para ulterior impressão ${ }^{6}$, ao serem disponibilizados na internet esses poemas incorporaram, além da animação, uma das principais características da interface computacional e seus objetos: a manipulação do objeto por parte leitor, ou, como outros denominam, a interatividade. Tal elemento presente no processo de leitura dos poemas de Vallias não implica num leitor absolutamente distinto daquele do de "livro impresso". Ao longo da leitura dos poemas que realizo a seguir, esse aspecto comum à poesia digital (a participação ou interferência do leitor na parte física da obra) será retomada. Aqui, é importante relembrar: além da criação realizada por meio de instrumentos digitais, Vallias preocupou-se posteriormente com apresentá-los numa forma e interface também digitais.

1.1 Nous n'avons pas compris Descartes: um diagrama metapoético

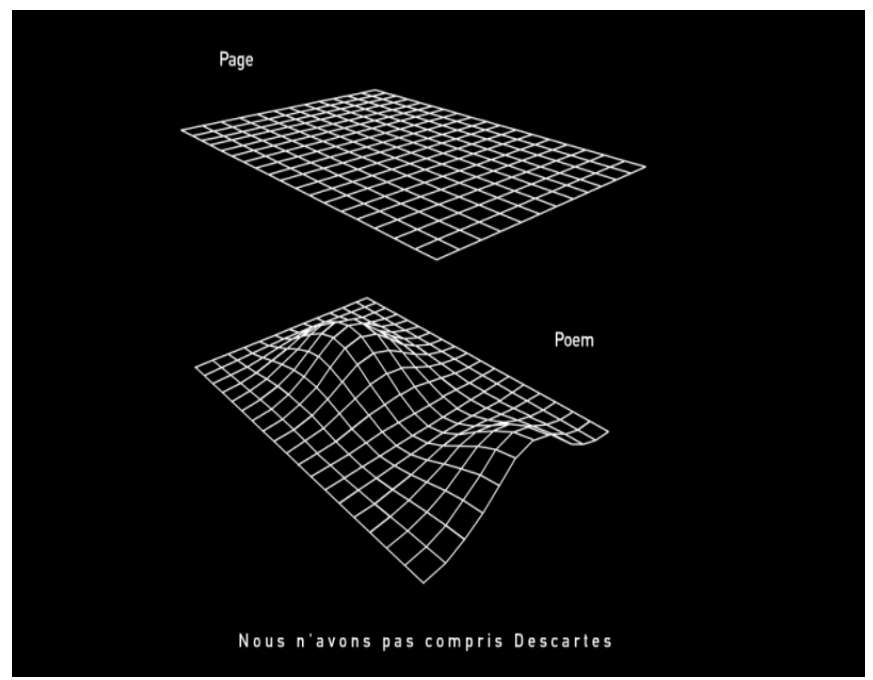

Imagem 1: Nous n'avons pas compris Descartes [captura de tela].

Criado em 1990, através do software AutoCAD, Nous n'avons pas compris Descartes assumiu um caráter de poema manifesto para André Vallias (1997).

${ }^{5}$ Transiente e intransiente são uma das categorias da Teoria Cibertextual de Espen Aarseth (1997/2005). Ele a define da seguinte forma: "se a simples passagem de tempo do utilizador provoca a aparição de "escritões", o texto é transiente; se assim não for, é intransiente. Alguns textos [...] desenrolam-se perante os utilizadores ao seu próprio ritmo, enquanto outros nada fazem sem serem activados pelo utilizador" (2005, p. 84).

${ }^{6}$ Uma característica que Manovich (2001) aponta como recorrente nas primeiras décadas após o surgimento do computador. 
Ele espelha exemplarmente a noção de "poema-diagrama", pois representa a relação que estabelece entre seus elementos gráficos e verbais. A imagem total do poema consiste em dois planos cartesianos que indicam as unidades "Page" e "Poem". O primeiro ("Page"), na parte superior, é bidimensional; o segundo ("Poem"), projeta duas curvas, sendo uma semi-completa.

A relação entre esses dois planos tematiza um perspectiva da criação poética que marcou, por exemplo, a chamada "poesia vanguardista" e experimental do século $X X$ - e que se estende para a poesia digital: o poema é percebido como o resultado de uma exploração criativa da mídia utilizada. Neste diagrama, o plano bidimensional e a palavra "Page" indicam a materialidade; o outro, não mais plano, mas revolvido, denso, tridimensional, representa a ação da criatividade sobre o meio. Dizendo de outro modo, através das palavras do poeta português Melo e Castro em Poética dos meios e Arte high tech: “... o suporte se torna substantivo e indissociável do poema porque só com ele o poema existe e sem ele o poema desaparece. A página em branco de Mallarmé, o espaço da Poesia Concreta, o corpo do Poeta-performance..." são exemplos desse "deslocar da atenção para a página": "página que é o espaço material do poema" (p. 21-22).

Nous n'avons pas compris Descartes pode ser visto, então, como um metapoema acerca da criação poética em sua relação com qualquer materialidade. Mas aqui nos interessa a relação com a materialidade particular utilizada pelo autor: o software de criação, o AutoCAD; ou o "digital" como um todo. A imagem total de Nous n'avons... é antes um espelho deste software que primeiro interessou a Vallias. Nele, ao invés da página bidimensional impressa temos um espaço imaterial que possibilita ligações infinitas entre suas coordenadas $x, y, z$. Ao explorar o espaço 3D da área virtual do software para posicionar o plano que representa a página, e ao construir o poema como um objeto também tridimensional, Vallias questiona não só a relação "materialidade e criação", mas também a materialidade em particular. 
A versão de Nous n'avons pas compris Descartes a qual hoje temos acesso não é exatamente igual à primeira, já que esta se destinou à posterior impressão - sendo o poema, portanto, estático. A remediação para a interface da web explora um aspecto que, como apontou Manovich (2011), é uma tendência dos objetos contemporâneos (que são, em larga escala, digitais): a apresentação da informação em forma de imagens animadas. O Nous n'avons... da web é, assim, mais caracteristicamente digital.

1.2 IO: Analysis: tecno-palavra-imagem-corpo

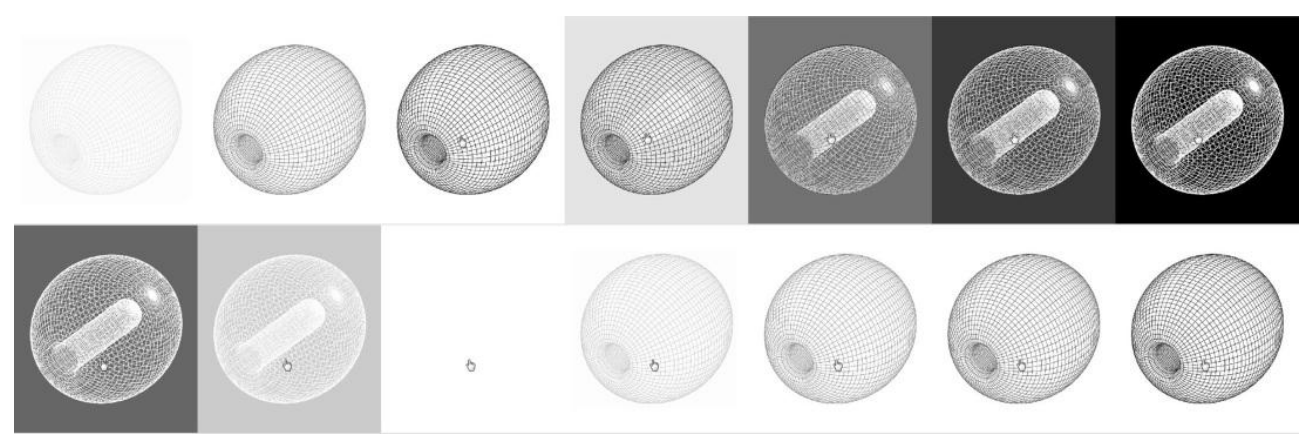

Imagem 2: IO: Analysis [montagem a partir de captura de tela].

IO faz parte do conjunto de poemas iniciais de Vallias criados com o auxílio do computador (início da década de 90). Refiro-me à fase pós-Desktop Publishing, que representou sua transição efetiva para a materialidade digital. Por não perceber uma diferença expressiva entre o tipo de criação que realizava com a malha serigráfica e com programas de editoração, foi com a descoberta dos softwares de desenho tridimensional que o mesmo começou a visualizar nas interfaces e ferramentas computacionais um meio diferencial de criação. Entretanto, Vallias faz uma ressalva:

An initial impetus towards construction of three-dimensional letters soon wore off. I could see no possibility of organic integration between the third dimension and the alphabetic code; it seemed to me that such a proceeding would lead to an iconization which, fundamentally, differed very little from the typographic experiments found in the visual poetry of the 1970 s and 1980 s. So instead I sought to integrate the third dimension into the syntax of the poem. $(2007$, p. 86) 
Ao invés do desenho de caracteres alfabéticos tridimensionais, Vallias utiliza a tridimensionalidade de duas outras formas: simulando-a ou projetando-a no "ambiente" ou "interface" de apresentação e realização do poema (assim como em Nous n'avons pas compris Descartes e Prthvî); e na construção dos objetos icônicos, que, em alguns de seus poemas, funcionam como a linguagem central de expressão, substituindo o uso predominante da linguagem verbal.

Uma primeira versão de $I O$ foi elaborada em 1991, a qual não temos acesso, e aparentemente compreendia apenas uma plotagem impressa em papel fotográfico ${ }^{7}$. Uma segunda versão, realizada em 1995, transformou este projeto visual em uma obra multimédia, composta de um objeto-texto que a partir da ação do leitor assumia texturas e posições variáveis, além de elementos sonoros e textos aleatoriamente apresentados. Vallias o descreve no artigo "We have not understood Descartes":

The poem "IO" (1995) was my first experiment with interactivity; in essence it is constructed and animated with Strata StudioPro software and integrated with Macromedia Director. The reader sets the poem off by making the spherical object move at choice in one of four directions - up, down, left, right. At a given moment a transformation takes place: the object's texture changes, from opaque to transparent, to show the cylindrical penetration within the sphere. This is accompanied by a sound background: the vocalization of "o" and " $\mathrm{i}$ ", in reference to the opaque and transparent worlds respectively, and the vocalization of the diphthongs "io" and "oi" at the change from one texture to another. At certain moments, chosen at random by the program, quotations and commentaries appear in relationship to the various meanings of the word "IO" - Italian for "I", the sign for Input/Output, numerals "1" and " 0 " - and excerpts from Hölderlin's translation of Sophocles' "Antigone", in which "io" appears as a phonetic transposition of an ancient Greek interjection indicating pain and lamentation (2007, p. 89-90).

Esta segunda versão de 10 , que ainda combinava outro elemento - a aleatoriedade -, não existe mais (ou já não roda nos novos sistemas dos computadores $^{8}$ ). A versão atual (s/d), disponível em seu site, não possui boa parte dos caracteres mencionados. Permanece o objeto principal, o globo que sugere as duas letras "I" e "O", com suas duas formas centrais, como mostra a

\footnotetext{
${ }^{7}$ Informação retirada de uma entrevista que integra o livro Cultura Digital.br (Savoni; Cohn. Orgs, 2009)

${ }^{8}$ Segundo indicação do autor em entrevista. Ver anexo.
} 
montagem no início do tópico. A vocalização dos ditongos ou qualquer outro aspecto sonoro foram excluídos. A atuação do leitor, que determinava a direção rotatória do globo, foi reduzida à ação de clicar para acionar a metamorfose do objeto, tornando a parte externa transparente e a interna visível - o jogo entre o externo, a superfície, a aparência (aqui sugeridos por um termo computacional: output - “O”), e o recluso, oculto, interior (input - "I"). Essas duas formas principais, dispostas sobre um fundo branco e preto, respectivamente, não dependem substancialmente da animação, e poderiam ser igualmente percebidas em sua forma impressa (a primeira versão).

As alterações feitas nessa terceira versão parecem atuar, dessa forma, de dois modos significativos. Em primeiro lugar, e em relação à segunda versão, o poema se torna estruturalmente mais simples. De uma versão que nos fornecia múltiplas unidades de informação, apresentando-nos as referências e possíveis sentidos da palavra-chave ("Italian for "I", the sign for Input/Output, numerals "1" and " 0 " - and excerpts from Hölderlin's translation of Sophocles' "Antigone", in which "io" appears as a phonetic transposition of an ancient Greek interjection indicating pain and lamentation"), 10 passou para uma versão de informação mínima: o poema é em preto-e-branco, o que nos lembra dos desenhos gráficos e estruturas arquitetônicas minimalista; não possui quadros sucessivos dotados de referências, como em outros de seus poemas ${ }^{9}$, ou imagens e sons que nos sugiram sentidos ou indiquem um caminho de interpretação, a exemplo de seus poemas Reza-brava para São Sebastião ${ }^{10}$ e Poema Civil $n^{\circ}$ $1^{11}$. Desse modo, ao reduzir as unidades de expressão Vallias deixa em aberto as possibilidades de interpretação e sentido de $I O$, já que não expõe a quais referências a "palavra" está relacionada. Ao não propor ou mesmo fixar estas ligações, como na sua versão anterior, o poema alcança uma abertura de interpretação que o torna, ao mesmo tempo, de difícil "decifração".

\footnotetext{
9 Ver, por exemplo, Hexaemeron. Disponível em: $<$ http://www.andrevallias.com/poemas/hexaemeron.htm>.

10 Disponível em: <http://www.erratica.com.br/opus/27/index.html>.

${ }^{11}$ Disponível em: <http://www.erratica.com.br/opus/65/index.html >.
} 
O segundo aspecto relevante acerca desta remediação, e agora em relação à primeira versão, diz respeito aos atributos que demonstram de que forma Vallias buscou explorar a mídia digital de exibição. $I O$, nesta forma atual, utiliza a capacidade de transiência do "espaço virtual" da tela; e, além disso, da possibilidade que esta confere ao usuário de, através de comandos, ativar ou configurar aspectos dessa transiência. Entretanto, diferente da segunda versão, que permitia ao leitor escolher ou influenciar elementos da aparência do poema, nesta última o leitor apenas ativa a passagem de uma imagem à outra. A distinção entre sua ação e aquela que realiza quando da leitura de um livro impresso, que aqui exercem função análoga, é apenas reflexo da diferença material elementar entre os dois média: a página impressa é estática - o leitor acessa as páginas do livro através da ação de virar a página; a tela do computador é interface de um espaço virtual transiente - o leitor acessa seu "conteúdo" através de cliques com o mouse (ou teclado).

Esta remediação coloca-nos diante de um contexto fronteiriço: ao mesmo tempo em que visualizamos $1 O$ tal como qualquer imagem impressa ou animação, também estamos diante de um objeto que se modifica a partir de uma intervenção nossa. Funkhouser, em Prehistoric Digital Poetry, o descreve como um "objeto virtual" (p. 142-143), que simula forma e características de um objeto concreto. Enquanto "objeto", pode ser "tocado”, “manipulado”. Vários outros poemas digitais tornam essa sensação de tatilidade mais complexa e melhor perceptível. O trabalho de Aya Karpinska em the arrival of the beeBox ${ }^{12}$, por exemplo, um poema-cubo em ambiente tridimensional, explora as combinações textuais a partir da ordenação espacial movida pelo leitor, através da rotação em até $360^{\circ}$ do cubo.

Sendo 10 um objeto-imagem interligado a uma expressão verbal, oscilando entre imagem, objeto e palavra, poderíamos dizer que o mesmo se aproxima das características de uma obra intermídia. Diferentemente de poemas em que seus componentes - texto verbal, som, imagens, linhas gráficas, etc. - estão

\footnotetext{
${ }^{12}$ Disponivel em: <http://www.technekai.com/box/beeBox.html>.
} 
separadamente dispostos ${ }^{13}$, de maneira que um não desestabiliza a identidade do outro, em $1 O$ a palavra se confunde com a imagem, alterando a forma como tradicionalmente a concebemos, e fazendo-nos questionar: 10 se configura enquanto palavra ou enquanto objeto? Ou os dois?

Como propõe Kiene Brillenburg Wurth, a obra intermídia "blends and rearranges familiar art forms in such a way as to make them indistinguishable and indivisible" (2006, p. 12). No poema $\mathrm{Nio}^{14}$, por exemplo, de Jim Andrews, a fusão entre letras e sons resulta num "rearranjo de formas" que torna as primeiras, seguindo o argumento de Wurth, algo diferente daquilo que representariam no âmbito impresso.

Podemos dizer que o mesmo se passa com o poema de Vallias. Apesar de ser por vezes sutil o modo como uma mídia integra-se a outro ao ponto de desestabilizar sua identidade, em 10 esta configuração torna-se sugestiva através de sua própria conjugação física - um imbricamento que aponta para a experimentação de outras formas, interfaces e funções da escrita. Como sugere Kiene Wurth acerca da tendência a uma complexa intermedialidade da poesia digital, nesta, "[the] words become like colors, colors like words, texts like buildings and spaces, sounds are spatially heard" (p. 15). Esta é uma das formas de percebermos $1 O$ no âmbito da poesia digital. Tal tendência, que não é nova à poesia, principalmente à poesia visual, reafirma a crescente conjugação entre a palavra e as artes plásticas - a pintura e escultura -, e a "tatilidade" dos painéis computacionais. A uma tecno-palavra-imagem-corpo, como propõe Janez Strehovec (2001): "word [...] with body, with substance, living a double life" (p.103).

1.3 Prthvĩ: diagrama sonoro e leitura volumétrica

13 O poema de Vallias Reza brava para São Sebastião serve-nos como um exemplo. Disponível em: <http://www.erratica.com.br/opus/27/index.html>.

14 Disponível em: <http://collection.eliterature.org/1/works/andrews nio.html>. 


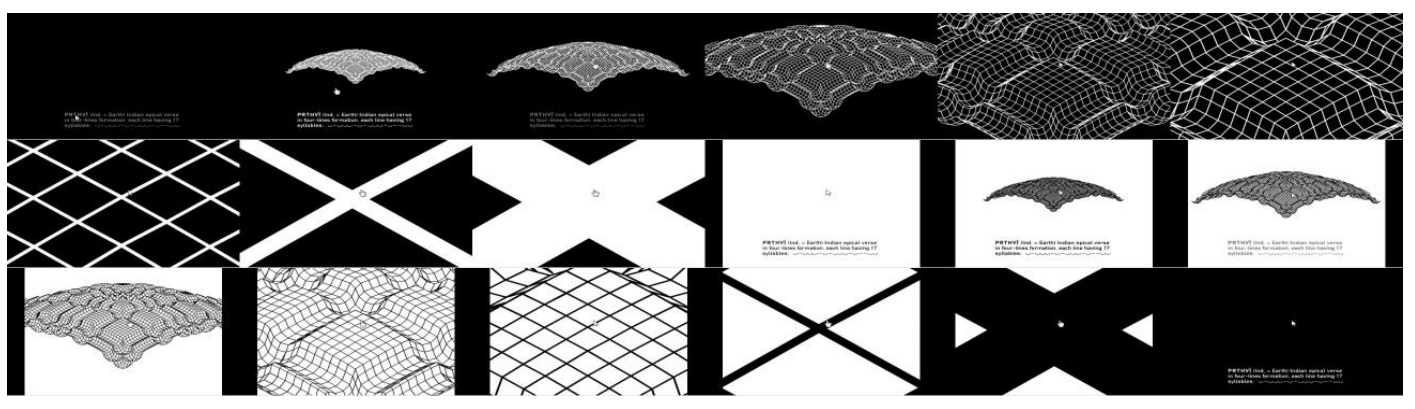

Imagem 3: Prthvī [montagem a partir de captura de tela].

Em Prthvī, a malha quadriculada de Nous n'avons pas compris Descartes, não mais plana, e sim tridimensional e semiesférica, dá forma a um objeto que representa a estrutura rítmica ${ }^{15}$ de uma métrica específica de poemas em sânscrito. Esta informação nos é brevemente fornecida pela legenda que "explica" o título: "PRTHVĪ (Ind. = Earth) Indian epical verse in four-lines

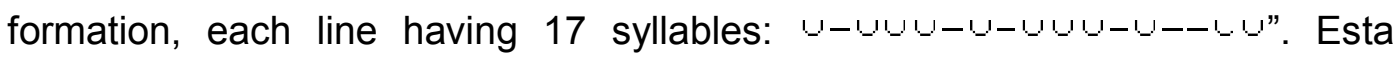
descrição das 17 sílabas refere-se à regra de composição do verso "prthvī", o qual, assim como predominantemente acontece com a composição dos versos em sânscrito, possui uma sequência determinada das sílabas longas e breves.

Há dois aspectos que merecem destaque em relação a Prthvī. O primeiro deles diz respeito à perspectiva poética de Vallias do poema enquanto "diagrama" perspectiva que se desenvolve essencialmente nesta série gráfica e que aqui se torna mais evidente. A primeira semelhança com os diagramas é a forma de relacionar uma estrutura gráfica com uma indicação verbal. Assim como em Nous n'avons pas compris Descartes e IO, as figuras dos poemas de Vallias concentram seus possíveis significados inicialmente no título, o que faz a linguagem verbal, mídia tradicional da construção poética, assumir um papel de "legenda", aparentemente secundário. Assim, a forma semiesférica de Prthvī só é compreensível pela indicação estabelecida no título ("Earth"), um tipo de realização formal que nos lembra dos caligramas de Guillaume Apollinaire. A segunda semelhança com os diagramas, e a mais importante, diz respeito ao

\footnotetext{
${ }^{15}$ Tal procedimento repete-se em outros poemas de Vallias. Ver, por exemplo: $A$ encantação pelo riso (disponível em: <http://www.andrevallias.com/poemas/encantacao.htm>) e Oratório (disponível em: <http://www.andrevallias.com/oratorio/>).
} 
modo de uso de uma estrutura gráfico-visual para representar, neste caso, uma forma poética de princípios definidos. Cada curva ou linha da malha semiesférica indica uma sílaba do verso em questão; se linha ou curva, representam um som longo ou breve, respectivamente. Este mesmo design poderia ser utilizado para outras formas de comunicação verbal que destacam em sua expressão um encadeamento rítmico. Bastante pertinente, dessa forma, para tratar a prosódia poética sânscrita.

Poderíamos dizer que Prthvī configura-se enquanto uma espécie de "diagrama sonoro". Apesar de não utilizar a linguagem verbal como linguagem de expressão, é o aspecto sonoro da palavra e do verso que o mesmo pretende retratar. De alguma forma semelhante à "leitura" de uma pauta musical, tentamos perceber um encadeamento rítmico onde só existem traços gráficos. Assim como o poema 10 , Prthvī retrata a possibilidade de uma linguagem ou uma esfera de signos "emergirem" através de uma mídia distinta daquele ao qual tradicionalmente estão ligados. Aqui, o aspecto sonoro da linguagem, o ritmo produzido pela sucessão de sílabas longas e breves insinua-se no desenho, na imagem, tal como em 10 o verbal insinua-se e confunde-se com o objeto. Ao utilizar procedimentos ou técnicas de diferentes áreas - como o desenho gráfico, a maquete ou desenho em 3D da arquitetura, os diagramas teóricos, etc. -, Vallias reconfigura suas formas e funções tradicionais, e aponta, através de uma referência quase "irônica" a uma estrutura poética clássica, para o que o próprio Vallias (2007) denomina "escrita aberta", ou um "diagrama aberto", "operando sob o signo da diversidade" (p. 88). Mais uma vez a noção de "intermidialidade" está presente, no modo como Kiene Wurth (2006) caracteriza a poesia digital.

O segundo aspecto que destaco assume a forma de um questionamento: de que forma a releitura animada de Prthvī (a versão atual) coaduna-se com a intenção aparentemente central do poema, que é a relação entre a figura gráfica e o título? Tal como já mencionado nos tópicos anteriores, a poesia digital (ou os objetos digitais como um todo) tende a configurar-se de modo 
semelhante às interfaces do computador. Nas palavras de Manovich, estas se caracterizam da seguinte forma:

Cultural interfaces try to balance the concept of a surface in painting, photography, cinema, and the printed page as something to be looked at, glanced at, read, but always from some distance, without interfering with it, with the concept of the surface in a computer interface as a virtual control panel, similar to the control panel on a car, plane or any other complex machine (2001, p. 96, versão em .pdf).

Esta citação é descritiva da estrutura do poema de Vallias. Vejamos: a proposição central de Prthvĩ nos é apresentada na imagem estática que é o primeiro quadro. Após sua visualização, ao mover o mouse sobre a tela o leitor perceberá que a figura gráfica possui uma estrutura "hipertextual", sendo mais próxima do stretchtext - tipo de apresentação textual na qual as informações estão concentradas na mesma página, diferentemente do hipertexto clássico, no qual somos direcionados para outras páginas através de hiperlinks. Entretanto, a cada novo clique na tela - ação que não atribui ao leitor nem uma função configurativa, nem exploratória, nem textônica (AARSETH, 2005), já que se assemelha ao tipo de participação no poema $10^{16}$ - a figura tridimensional da semiesfera amplia-se (o efeito zoom), move-se no eixo que é sua propriedade diferencial. A representação tridimensional ganha um tipo de visualização "apropriada", que acentua sua estrutura, e que Rita Rayley (2006) demoninaria "deep reading": "reading volumetrically, reading surface to depth and back again"17. Não há, em Prthvī, "informações" novas geradas pela exploração desse terceiro eixo, como nos projetos (citados por Rayley) Screen $^{18}$ (projetado em Cave), de Noah Wardrip-Fruin, ou a série em Java Click Poetry: Words in Space ${ }^{19}$, de David Knoebel. Ela atua de modo autorrefencial, como nos poemas anteriores: a escrita em 3D, forma que

\footnotetext{
${ }^{16}$ Relembrando: a ação do leitor em 10 e em Prthvī é apenas fruto da estrutura intrasiente do poema, ou do fato das interfaces computacionais funcionarem a partir de comandos do usuário. Não há a possibilidade de escolhas, como existe em outro poema gráfico-digital de Vallias, o De verso (Disponível em: <http://www.andrevallias.com/deverso/deverso.htm>).

${ }_{17}$ Disponível em: <http://iowareview.uiowa.edu/TIRW/TIRW Archive/september06/raley/editorsintro.html>.

18 Fragmentos em vídeo disponíveis em: <http://collection.eliterature.org/2/works/wardripfruin screen.html>.

${ }^{19}$ Disponível em: < http://home.ptd.net/ clkpoet/cpwis.html>.
} 
chamou a atenção de Vallias quando de seus primeiros poemas digitais, exige uma leitura que corresponda ao seu meio. Não é esta uma das preocupações centrais da literatura e poesia digitais? Como propôs Melo e Castro em prefácio ao livro Poesia Eletrônica: negociações com os processos digitais, de Jorge Luiz Antonio: estamos diante de uma nova literacia.

\section{Considerações Finais}

É interessante observar como as primeiras formas da poesia digital de Vallias, ainda na década de 90 , se voltam justamente para um questionamento complexo das mídias - principalmente da mídia tradicional de composição poética, a linguagem verbal -, fato que caracteriza um dos maiores interesses dos poetas digitais atuais. Mas parece ser justamente esta intermidialidade esse imbricamento de mídias, de gêneros artísticos que os leva a rever os limites formais de cada um - que confere à poesia digital a complexidade que observamos, dificultando ainda mais a abrangência de sua recepção.

É por esta razão que Melo e Castro (2008), por exemplo, afirma a necessidade de uma nova literacia, da aprendizagem de uma nova forma de "escrever" e de "ler". Voltados para essa intenção, os leitores de poesia digital, e não só, podem encontrar na poesia inicial de André Vallias uma fonte de questionamento dessas novas formas de comunicação, de elaboração poética e de leitura. Desse modo, a noção de diagrama aberto proposta por Vallias é uma estrutura de criação que encontra forte respaldo nos objetos contemporâneos, e também auxilia-nos a melhor compreendê-los. Como propõe Katherine Hayles no livro Electronic Literature, referindo-se não especificamente à poesia digital, mas à literatura eletrônica como um todo: "electronic literature can be seen as a cultural force helping to shape subjectivity in na era when networked and programmable media are catalyzing cultural, political, and economic changes with unprecedented speed" (2008, p. 37). A visão de Vallias da poesia como um diagrama aberto, multimédia, faz coro a esta observação de Hayles, e aponta para aquilo que Vilém Flusser, filósofo que impulsionou a sua criação digital, chamava de abertura do 
pensamento para outros códigos (o pensamento poder se manifestar através de outros códigos), liberto da dominação da linguagem verbal e da escrita. Neste sentido, vejo na poesia digital de André Vallias um percurso inicial e importante para visualizarmos e discutirmos essa abertura.

\section{THE POEM AS AN OPEN DIAGRAM: ANDRÉ VALLIAS' GRAPHICAL DIGITAL POETRY}

ABSTRACT: The poet André Vallias is one of the pioneers of digital poetry. In 1991, alongside Friedrich Block, he was the curator of the "First International Exhibition of Digital Poetry", P0es1s, and has published multimedia and hypermedia poems in national and international sites and anthologies. In the paper "Nous n'avons pas compris Descartes", Vallias defined a conception of poem which has guided his first digital poetry series - graphic poems, diagram-poems -, as has resumed his following multimedia and hypermedia projects. This conception conceives the poem as an "open diagram", a poem that is constructed under an inter-relationship of codes, far from the verbal signal hegemony, and endowed with intermediality. This article proposes an interpretation of three poems of this first series, which were developed with AutoCad software and lately remediated to the Web interface. The interpretations look to point out, in the first place, some possible meanings of each poem; and, following, the relation between some characteristics of these poems and digital poetic aspects as a whole.

KEYWORDS: André Vallias. Diagram-poem. Digital poetry. Intermediality.

\section{REFERÊNCIAS}

AARSETH, E. Cibertexto - Perspectivas sobre literatura ergódica. Lisboa: Pedra de Roseta, 2005.

ANDREWS, J. NIO. In: HAYLES, Katherine; NICK, Montfort; SCOTT, Rettberg; STEPHANIE; Strickland, (Ed.). The Electronic Literature Collection. V. 1. Maryland: Electronic Literature Organization, 2011. Disponível em: <http://collection.eliterature.org/1/works/andrews_nio.html>. Acesso em: 14 mai. 2013.

BLOCK, F. W. Eight Digits of Digital Poetics. In: Block, F. W.; Heilbach, C.; Wenz, K. (Ed.). The Aesthetics of Digital Poetry.. Ostfildern-Ruit: Hatjie Cantz Verlag, 2004. , p. 307-17.

CASTRO, E. M. de M. e. Poética dos meios e arte high tech. Lisboa: Veja, 1988.

CASTRO, E. M. de M. e. Para uma outra literacia [Prefácio]. In: ANTONIO, J. L. Poesia eletrônica: negociações com os processos digitais. Belo Horizonte: Veredeas \& Cenários, 2008. p. 7-10.

FLUSSER, V. Há um futura para escrita?. São Paulo: Annablume, 2010. 
FUNKHOUSER, C. T. Prehistoric Digital Poetry: An Archaeology of Forms, 1959-1995. Tuscaloosa: University of Alabama Press, 2007.

HAYLES, N. K.. Electronic Literature: New Horizons for the Literary. Notre Dame: University of Notre Dame, 2008.

MANOVICH, L. The language of new media [versão pdf]. 2001. Disponível em: <http://www.manovich.net/LNM/Manovich.pdf>. Acesso em: 14 mai. 2013.

PACKER, R.; JORDAN, K. (Ed.). Multimedia: From Wagner to Virtual Reality. New York: W.W. Norton, 2001.

PIGNATARI, D. Semiótica \& Literatura: icônico e verbal, Oriente e Ocidente. São Paulo: Cortez \& Moraes, 1979.

RITA, R. Writing 3D. Special Issue of lowa Review. 2006. Disponível em: $<$ http://iowareview.uiowa.edu/TIRW/TIRW_Archive/september06/raley/editorsint ro.html>. Acesso em: 14 mai. 2013.

STREHOVEC, J. The Moving Word: Towards The Theory of Web Literary Objects. In: Cybertext Yearbook 2000. 2001. p. 100-116. Disponível em: <http://cybertext.hum.jyu.fi/articles/126.pdf>. Acesso em: 14 mai. 2013.

VALLIAS, A. We have not understood Descartes. In: KAC, Eduardo. (Ed.). Media Poetry: An international Anthology. Chicago: Intellect Books, 2007. p. 86-91.

Nous n'avons pas compris Descartes. 1997. Disponível em: <http://www.andrevallias.com/poemas/nous.htm>. Acesso em: 14 mai. 2013.

. Oratório. 2004.2 Disponível em: $\overline{<h t t p: / / w w w . a n d r e v a l l i a s . c o m / o r a t o r i o />. ~ A c e s s o ~ e m: ~} 14$ mai. 2013.

$\begin{array}{ccc}\text {. Poema Civil } \mathrm{n}^{\circ} 1 . & \text { In: VALLIAS, André; FERRAZ, Eucanaã. (Ed.). } \\ \text { Errática. } & \text { Disponível } & \text { em: }\end{array}$ <http://www.erratica.com.br/opus/65/index.html>. Acesso em: 14 mai. 2013.

A frase de Flusser. 2012. Disponível em: <http://twextra.com/agxl8y>. Acesso em: 14 mai. 2013.

A encantação pelo riso. 2003. Disponível em: <http://www.andrevallias.com/poemas/encantacao.htm>. Acesso em: 14 mai. 2013.

. De verso. Sem data. Disponível em: <http://www.andrevallias.com/deverso/deverso.htm>. Acesso em: 14 mai. 2013. 
. Hexaemeron. Sem data. Disponível em: <http://www.andrevallias.com/poemas/hexaemeron.htm>. Acesso em: 14 mai. 2013.

IO. Sem data. Disponível em:

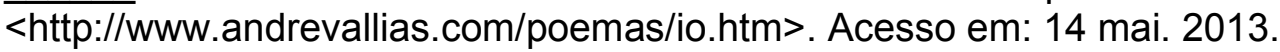

Prthvī. Sem data. Disponível em:

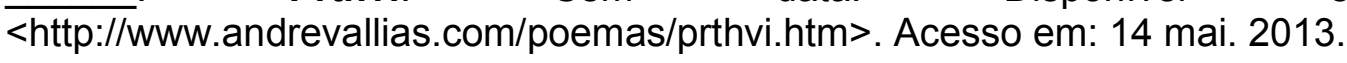

. Reza-brava para São Sebastião. Sem data. In: VALLIAS, André;

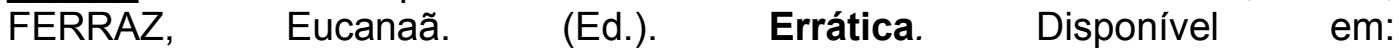
<http://www.erratica.com.br/opus/27/index.html>. Acesso em: 14 mai. 2013.

WURTH, K. B. - Multimediality, Intermediality, and Medially Complex Digital Poetry. RiLUnE, n. 5, p. 1-18, 2006. Disponível em: <http://www.rilune.org/mono5/3_brillenburg.pdf>. Acesso em: 14 mai. 2013.

Texto enviado em maio de 2013.

Texto aprovado em julho de 2013. 